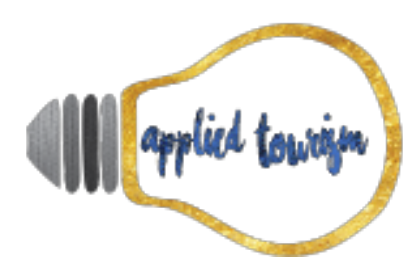

Volume 3, número 1, 2018, p. 36-57

\title{
MÉDICO DESCANSA? Uma análise sociocultural do lazer e turismo de médicos em Dourados/MS
}

\author{
Larissa Clemente Correia \\ Graduanda em Turismo \\ Universidade Estadual de Mato Grosso do Sul \\ laaricorreia@hotmail.com \\ Alice Pillon Ribeiro \\ Graduanda em Turismo \\ Universidade Estadual de Mato Grosso do Sul \\ alicepillon@hotmail.com
}

Taisa Ellen Dias de Oliveira

Mato Grosso do Sul

taisa_ellen@hotmail.com

Graduanda em Turismo

Universidade Estadual de

Camila de Brito Quadros Lara

Mestranda em História

Universidade Estadual de Mato Grosso do Sul

camilaq21@hotmail.com

Recebido: 28 de junho, 2017

Aprovado: 18 de setembro, 2017

\section{RESUMO}

O presente artigo tem como temática a análise sociocultural das práticas de lazer e de turismo de um grupo de médicos da cidade de Dourados/MS. O objetivo geral da pesquisa foi verificar como esses médicos utilizam seu tempo livre e quanto desse tempo é utilizado com prática de atividades de lazer e de turismo, além da autoavaliação sobre o lazer praticado pelos respondentes. A metodologia utilizada pautou-se na pesquisa bibliográfica inicial sobre o tema, confecção e aplicação do instrumento de pesquisa de campo, tendo como método o questionário e a análise qualitativa dos dados. Nesse sentido, entende-se como fundamental para o profissional do turismo, compreender o lazer dos diferentes grupos sociais com os quais irá trabalhar e, no caso desta pesquisa, pensar em atividades de lazer e de turismo que sejam adequadas à rotina dos médicos, além de despertar a consciência para a importância do lazer enquanto qualidade de vida.

Palavras-chaves: Médicos; lazer; Dourados/MS. 


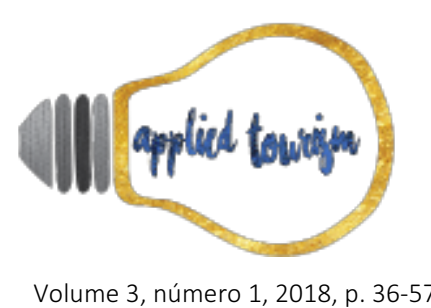

\section{INTRODUÇÃO}

O presente trabalho tem como temática a análise sociocultural das práticas de lazer de um grupo de médicos que trabalham em equipamentos públicos e particulares na cidade de Dourados/MS. O objetivo geral foi verificar como os médicos compreendiam seu tempo livre, de que modo utilizavam esse tempo e, ainda, qual parte desse tempo era destinada à prática de atividades de lazer e de turismo. Nesse sentido, buscou-se responder a algumas questões problematizadoras, dentre as quais: "Qual é a carga horária média de trabalho semanal? O que costuma fazer em dias de folga ou períodos de férias? A renda média desses trabalhadores tem relação com o tipo de lazer realizado pelos mesmos?" "Quais práticas de lazer gostariam de realizar caso tivessem mais disponibilidade de tempo ou dinheiro?".

A metodologia utilizada pautou-se na pesquisa bibliográfica inicial sobre a temática "lazer dos médicos", confecção e aplicação de instrumento de pesquisa de campo, neste caso, aplicando-se vinte e dois questionários para médicos de equipamentos públicos e particulares da cidade e posterior produção e apresentação de relatório final com a análise dos dados, bem como as considerações sobre as especificidades do segmento pesquisado.

Nesse sentido, espera-se que, através desta atividade, tenha-se dado um passo inicial na pesquisa sociocultural dos diferentes segmentos sociais com os quais o profissional de turismo estará em contato durante o desempenho de suas funções, sobretudo os que irão trabalhar com o lazer e turismo. Além disso, também se almeja contribuir para a reflexão pessoal desses profissionais sobre suas demandas de trabalho e o tempo livre dedicado às atividades de lazer, adequando-as à sua própria qualidade de vida.

Salienta-se ainda, que este artigo é o resultado de uma atividade semestral final coordenada pela disciplina Sociologia do Lazer e do Turismo, do curso de Turismo da Universidade Estadual de Mato Grosso do Sul - campus Dourados, que propiciou que os acadêmicos estudassem, além da teoria abordada em sala de aula, as práticas de lazer e turismo voltadas para os diferentes segmentos sociais do estado de Mato Grosso do Sul. 


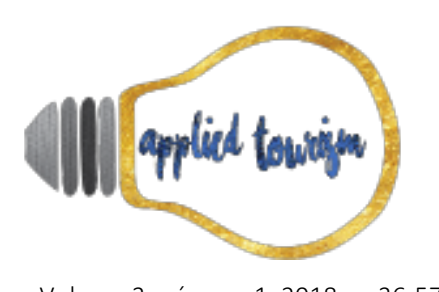

Volume 3, número 1, 2018, p. 36-57

\section{Lazer, trabalho e tempo livre: breves considerações}

A palavra lazer deriva do latim licere, ou seja, "ser lícito", "ser permitido". Em português é lazer, em inglês é leisure, em francês é loisir, em italiano, espanhol e alemão não tem vocábulo semelhante, utiliza-se a palavra 'ócio’ com o sentido de lazer. Nesse sentido, podese dizer que lazer está relacionado à: descanso de trabalho; folga; vagar; lapso de tempo em que se descansa; ociosidade: falta de ocupação.

Porém, Dumazedier (1999, p. 236) contrapõe essa afirmação, reiterando a diferença entre ócio e lazer. "O lazer não é a ociosidade, pois que ele supõe, antes de qualquer coisa, a presença do trabalho profissional, ao passo que a ociosidade, supõe em primeiro lugar, a negação deste".

Segundo Domênico de Masi (2000), autor dos livros "Ócio Criativo" e "Economia do Ócio": "É necessário aprender que o trabalho não é tudo na vida e que existem outros grandes valores: o estudo para produzir saber; a diversão para produzir alegria; o sexo para produzir prazer; a família para produzir solidariedade etc." (De Masi, 2000, p. 75). Além disso, poderíamos definir lazer dentro dessa concepção, como uma forma do indivíduo utilizar seu tempo dedicando-se a uma atividade que goste de fazer, o que não significa que seja sempre uma mesma atividade. Esta pode ser uma entre tantas outras.

Quando gastamos nossas energias no trabalho, esquecemos que precisamos também de energia para o lazer. Porém, sabe-se que o lazer relaciona-se intrinsecamente com o trabalho e vice-versa, não podendo ser desvinculados tais conceitos e desdobramentos em nossa sociedade contemporânea. Assim, podemos definir trabalho como qualquer atividade física ou intelectual, realizada pelo ser humano, cujo objetivo é fazer, transformar ou obter algo. Compreendendo tais atividades correspondentes à: aplicação das forças e faculdades humanas para alcançar um determinado fim; e, atividade coordenada, de caráter físico e/ou intelectual, necessária à realização de qualquer tarefa, serviço ou empreendimento. Nesse contexto, o tempo livre passa a ser definido em oposição ao trabalho, é o tempo onde não estamos trabalhando, são os momentos livres, de "não trabalho". Camargo (1999) aborda que as atividades de lazer têm alguns aspectos e propriedades semelhantes, que permitem reuni-las sob a mesma designação, sendo elas: 


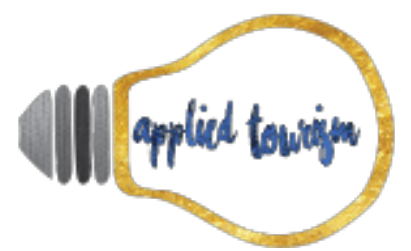

Volume 3, número 1, 2018, p. 36-57

Escolha pessoal: há um grau de liberdade nas escolhas dentro do lazer, maior que as escolhas que se faz no trabalho, no ritual familiar, na vida sociorreligiosa e sociopolítica. Por livre escolha no lazer, entenda-se assim a existência de um tempo precioso onde se pode exercitar com mais criatividade as alternativas de ação ou de participação.

Gratuidade: o lazer nunca é inteiramente gratuito. Apenas o é mais do que um ato da rotina profissional, quando o indivíduo está de olho na remuneração, ou do que levar o filho ao médico, para exame. Contudo, é um tempo onde se pode exercitar mais o fazer por fazer, sem que necessariamente haja um ganho financeiro em vista ou um preço sério a pagar.

Prazer: em toda escolha de lazer, existe o princípio da busca do prazer, mesmo que a atividade inicie com um esforço, para se obter o relaxamento agradável ou a sensação posterior de estar em forma; ou que termine no tédio, que a boa conversa e os copos de bebida não conseguiriam evitar. Liberação: o lazer é sempre liberatório de obrigações; busca compensar ou substituir algum esforço que a vida social impõe (Camargo, 1999, pp. 10-14).

Goldenstein (2011) aborda essa questão relacionando-a com sua pesquisa de campo junto a médicos, relatando que os mesmos deixam de cuidar de si, e acabam dedicando-se quase que exclusivamente ao trabalho.

Entre os médicos entrevistados esse cuidado também é negligenciado e só se faz presente no momento da percepção da temporalidade, da finitude, gerando medo. O exagero, ou trabalho excessivo, está sempre presente e é, sob certo aspecto, negligenciado. Uma das médicas chega a dizer que não há tempo disponível para ir ao médico e fazer exames clínicos (Goldenstein, 2011, p. 143).

Segundo De Masi (2000, p. 89), "o homem precisa aprender a desfrutar do seu tempo livre, pois a tendência mundial é de que as pessoas passem a ter mais horas disponíveis e será necessário que elas se adaptem a esta tendência que aos poucos vai se instaurando". Nessa perspectiva, o lazer é conceituado como "um conjunto de atividades desenvolvidas pelos indivíduos seja para o descanso, seja para o divertimento, seja para o seu desenvolvimento pessoal e social, após cumpridas suas obrigações profissionais, familiares e sociais" (Dumazedier, 1976, p. 34).

Para Dumazedier (1976, p. 35), lazer tem relação com o que chama de "3 Ds", sendo explicado por ele como: 


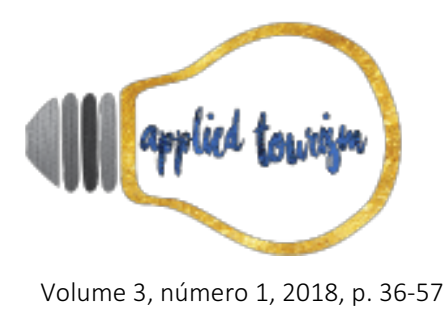

- $\quad 1^{\circ}$ D -: Divertimento: ato ou efeito de divertir(-se); algo que serve para divertir. Aquilo que diverte; diversão, distração, entretenimento = ato ou efeito de entreter(-se), de distrair(-se). Aquilo que distrai, entretém; distração, divertimento.

- $\quad 2^{\circ} \mathrm{D}$ - Descanso - cessação de uma dada atividade; trégua; pausa, interrupção. Folga no trabalho.

- $\quad 3{ }^{\circ}$ D- Desenvolvimento pessoal e social: processo de crescimento na direção da melhoria da qualidade das relações das pessoas: consigo mesmas, com o outro, com os grupos dos quais participa, com a natureza.

Após anos de estudos dedicados à área do lazer e suas observações inerentes à pesquisa empírica, Dumazedier (1980) chega a uma categorização dos interesses ou atividades de lazer que servem de referência aos principais estudos sobre lazer, que seriam:

- $\quad$ Físicas/esportivas, como a caminhada, a ginástica e o esporte;

- $\quad$ Manuais, como a bricolagem, os cuidados com plantas e animais domésticos;

- Intelectuais, como a busca de conteúdos do conhecimento regulada apenas por necessidades lúdicas ou não instrumentais;

- $\quad$ Artístico-culturais, como o espetáculo, a dança, as artes plásticas, o cinema e o teatro; - Associativas/sociais, como a participação em grupos informais e formais associações de bairro, as rodas de tereré tão presentes no estado de Mato Grosso do Sul, as festas familiares;

Nesse sentido, outros autores também contribuem com reflexões mais atuais nesse campo. Luiz Octávio de Lima Camargo (1998) propõe outra categoria de lazer, tendo por base o interesse:

- $\quad$ Turístico - como as viagens, pequenos passeios, visitação turística;

E a pesquisadora Gisele Schwartz (2003) insere o campo virtual nesse contexto, destacando o interesse:

- $\quad$ Virtual - jogos virtuais e todos os tipos de lazeres virtuais. 


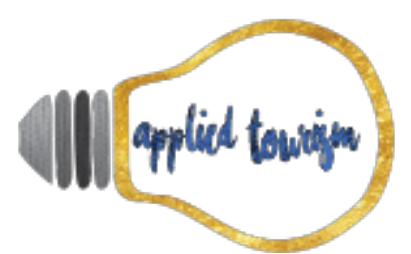

Volume 3, número 1, 2018, p. 36-57

\section{Médico descansa? Ponderações sobre o lazer desse grupo social em Dourados/MS}

O pesquisador Eduardo Goldenstein (2011, p. 11) apresenta em sua tese na área da Psicologia, importantes contribuições acerca do tema lazer dedicadas ao grupo social e profissional "médicos". Para o autor,

A escolha do lazer dos médicos para um tema para a uma pesquisa acadêmica pode parecer à primeira vista algo bastante inusitado. Afinal, nos preocupamos muito mais com o trabalho médico em si, com as dificuldades inerentes ao mesmo, com o stress e o burn-out dos médicos e suas repercussões no dia a dia dos pacientes, com os conflitos nas relações médico-paciente, do que com a vida privada dos médicos. Os médicos só "existem" quando trabalham; não os enxergamos quando descansam.

Nesse sentido, o pesquisador revela a importância de se dedicar aos estudos do lazer da classe médica, pois segundo Goldenstein (2013, p. 9), essa ideia é

Para muitos uma surpresa, talvez algo irreal, uma realidade inexistente. Medicina é um sacerdócio, está associada a muito trabalho, muita dedicação, sem hora para começar ou terminar. Esse é o pensamento incutido não só na cabeça dos leigos, mas também dos próprios médicos. Médico dá plantão, emenda dia com noite e noite com dia. Entretanto, médico tem necessidades inerentes a qualquer ser humano, precisa dormir, descansar, curtir a família, ter uma vida social e sexual, precisa sair, se divertir. Ou até não fazer nada. Médico precisa de lazer. Sem isso, é impossível a ele "compreender" o adoecimento, o sofrer, o reestruturar-se no pós-doença.

Nessa perspectiva, "o lazer surge assim mais do que uma necessidade, mais do que uma reivindicação, ele se torna um direito da pessoa humana, que passa a vivenciálo como um valor" (Rolim, 1989, p. 56). Em relação à questão do valor do lazer para o desenvolvimento e qualidade de vida do ser humano, o mesmo autor aborda que:

Na mutação de valores, o lazer emerge como um valor novo, antítese do valor trabalho. Tempo desobrigado não só dos afazeres profissionais, mas domésticos, sociopolíticos e religiosos. Pertence ao homem e este o emprega na sua própria realização. Valor novo porque marcado das propriedades: liberdade, gratuidade, pessoalidade e hedonismo, inexistentes no valor trabalho, onde impera a obrigatoriedade profissional, o lucro, o anonimato e o dever (Rolim, 1989, p. 104). 


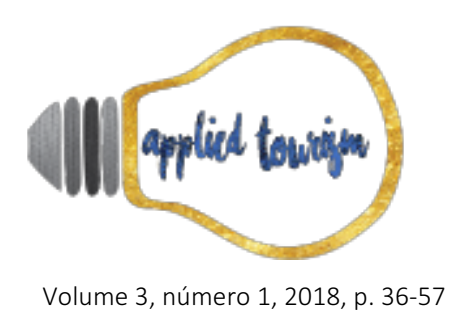

\section{Metodologia de pesquisa}

Esse artigo é resultado de um projeto que foi proposto em sala de aula para os acadêmicos do primeiro ano do curso de Turismo da Universidade Estadual de Mato Grosso do Sul UEMS, campus Dourados, como requisito parcial avaliativo da disciplina "Sociologia do Lazer e do Turismo". Dessa forma, os acadêmicos foram divididos em grupos para pesquisar o tempo livre de alguns segmentos sociais de Dourados, sendo permitido aos acadêmicos que morassem nas cidades próximas à Dourados realizarem sua pesquisa nas mesmas.

Dessa forma, definiu-se a temática e o segmento no qual o grupo iria trabalhar, nesse caso, os médicos da cidade. Iniciaram-se as pesquisas bibliográficas relativas ao tema em questão e paralelamente ocorreu a criação do instrumento de pesquisa a campo, o questionário que seria aplicado aos médicos. Em relação ao questionário, que foi desenvolvido com dez questões fechadas e uma questão aberta, as cinco primeiras perguntas dizem respeito ao perfil sociocultural dos respondentes, inserindo-se questões relacionadas a: sexo, faixa etária, estado civil, grau de instrução e média de renda familiar. As outras questões indagavam os médicos a respeito de sua carga horária de trabalho semana, folga e descansos semanais, férias e atividades de lazer.

Desse modo, o grupo de acadêmicos foi a campo e conseguiu aplicar vinte e dois questionários, sendo realizados em dois hospitais particulares e em dois postos de saúde da cidade de Dourados. Após a aplicação dos questionários, os dados foram tabulados e convertidos em gráficos, para melhor adequação e explanação dos resultados obtidos. Tais resultados foram apresentados em forma de relatório final (parte escrita) e seminários (parte oral) para todos os colegas de sala. Salienta-se, ainda, que foram pesquisados outros segmentos, como por exemplo: professores, comerciários e idosos usuários de Centros de Convivência em Dourados/MS.

Esta foi a primeira experiência de pesquisa prática realizada pelos acadêmicos do primeiro ano do curso em 2016 e, dessa forma, a docente da disciplina Sociologia do Lazer e do 


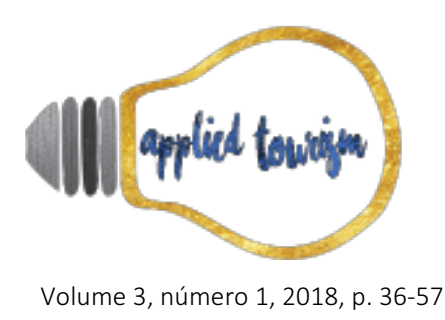

Turismo acompanhou e orientou os trabalhos no sentido de facilitar a empreitada a campo, bem como as implicações das relações socioculturais que se fizeram presentes durante a aplicação dos questionários. Percebeu-se, assim, a importância de iniciativas que desenvolvam os sentidos do pesquisador das Ciências Sociais, pois, desse modo, compreende-se melhor a ocorrência das interações entre os indivíduos, bem como suas implicações.

Em relação às percepções na atividade de aplicação dos questionários, nota-se como é complexo o profissional médico dispor de um tempo livre para responder a essa demanda, ocorrendo inclusive várias negativas em responder aos questionários. Tal fato provavelmente deve-se a inúmeras questões evidenciadas durante as conversas informais entre o grupo de pesquisadores e entre pesquisador e pesquisado: falta de um tempo de paradas entre consultas e atendimentos aos pacientes, falta de interesse na pesquisa, indisposição com os gestores públicos (na ocasião, os médicos dos postos de saúde estavam há meses sem receber salários), rotina extremamente corrida e atribulada, dentre outros fatores.

\section{RESULTADOS OBTIDOS}

No intuito de se pesquisar o tempo livre e as práticas de lazer do segmento social "médicos" na cidade de Dourados/MS, o instrumento de pesquisa foi elaborado de forma que se analisassem e discutissem as principais questões relacionadas à temática abordada. Assim, vinte e dois questionários foram aplicados, sendo realizados em dois hospitais particulares e em dois postos de saúde da cidade de Dourados. Após a aplicação dos questionários, os dados foram tabulados e convertidos em gráficos, para melhor adequação e explanação dos resultados obtidos. As primeiras cinco questões objetivaram traçar um possível perfil sociocultural do segmento pesquisado, inserindo-se questões relacionadas ao: sexo, faixa etária, estado civil, grau de instrução e média de renda familiar. Tais resultados são descritos e analisados abaixo (Figura 01), salientando-se que todos os gráficos foram elaborados pelas autoras deste artigo. 
Figura 1 - Perfil Demográfico
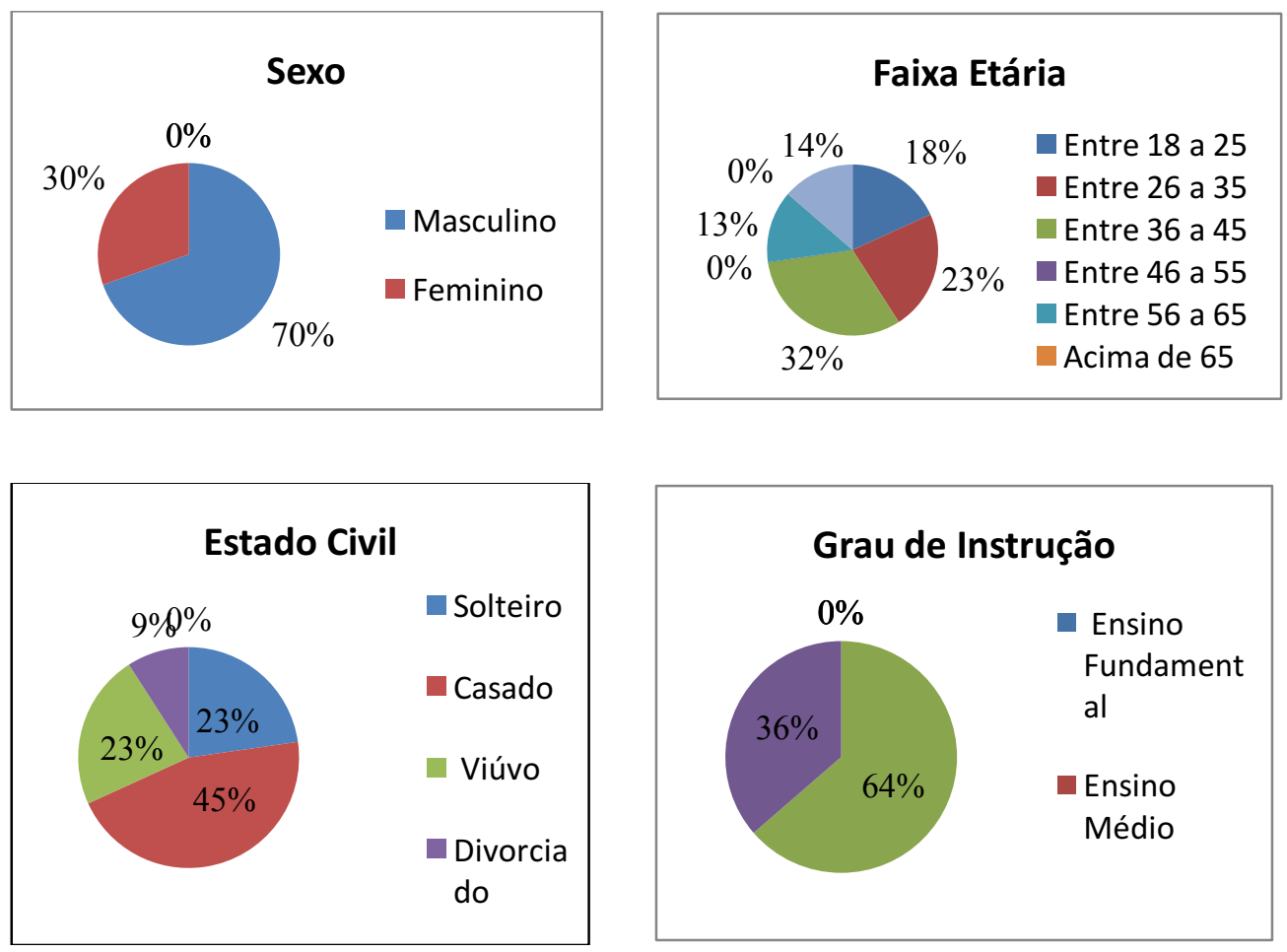

\section{Média total da renda familiar - \\ Salário Mínimo = R\$ 788,00 (2016)}

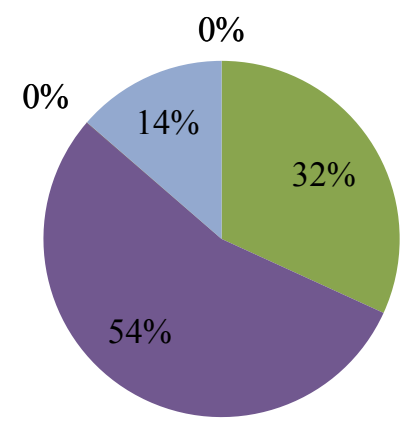

0 a 1 S.M.

1 a 3 S.M.

- 3 a 6 S.M.

6 à 10 S.M.

mais de 10 S.M.

Não Possui Renda

Não Citou

Fonte: Autores (2017).

Nesse sentido, temos que o perfil sociocultural do segmento pesquisado é formado basicamente por médicos que: em sua maioria são homens, com uma faixa etária bastante diversificada, porém majoritariamente entre 36 e 45 anos, grande parte casada, 


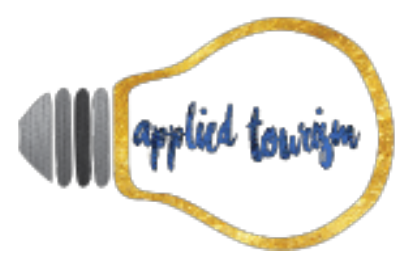

Volume 3, número 1, 2018, p. 36-57

com ensino superior e pós-graduação. O dado que chamou a atenção é logicamente a questão do grau de instrução, pois se sabe que o curso superior de Medicina também exige que o concluinte faça sua especialização em alguma área específica, como por exemplo: cardiologia, oftalmologia, ortopedia, cirurgia geral etc.

Figura 1 - Carga horária de trabalho e intervalos de folga e descanso.
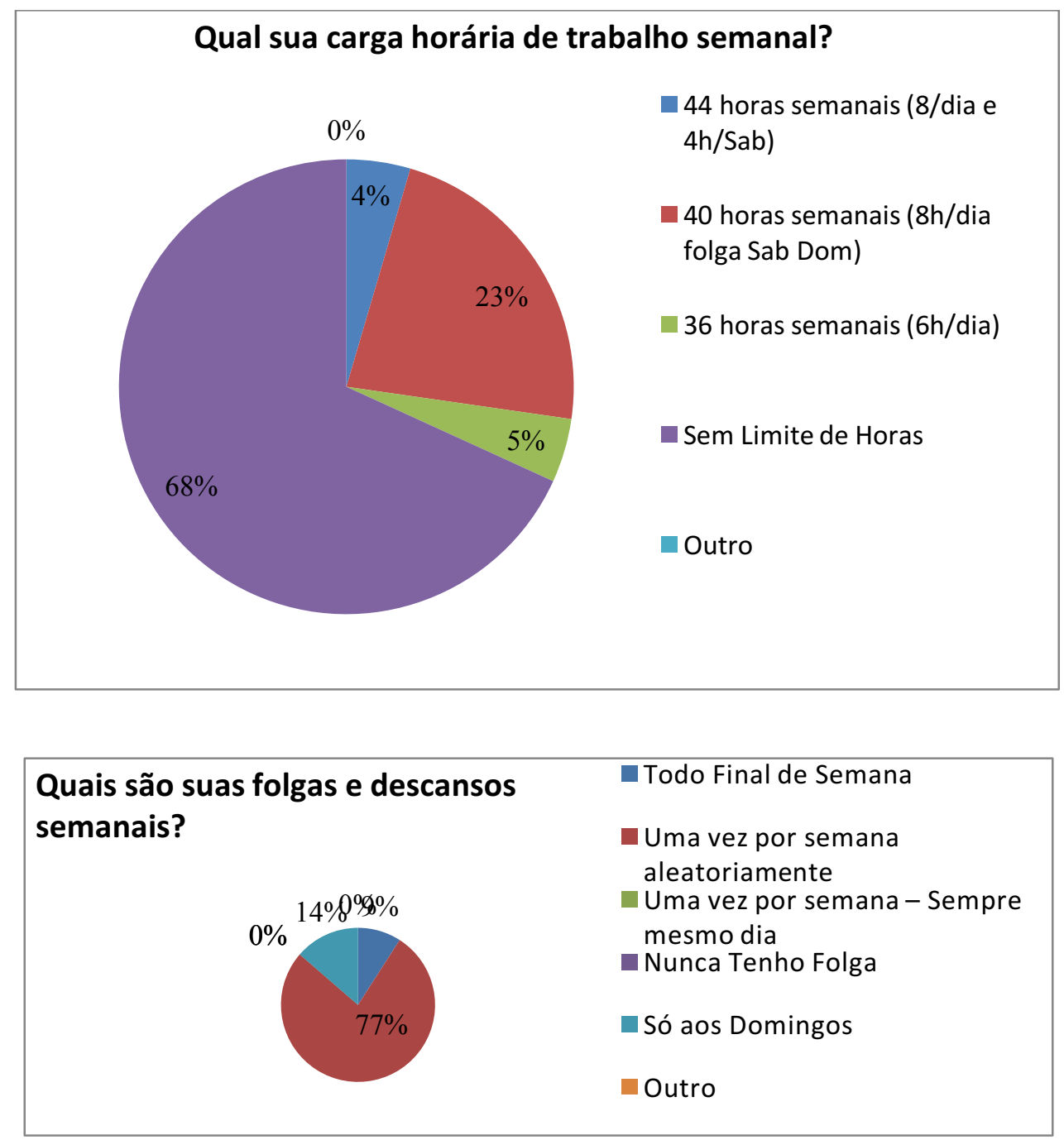

Fonte: Autores (2017).

Indagados sobre a carga horária de trabalho semanal, a maioria evidenciou que não tem limites de horas para trabalhar por semana, demonstrando, assim, um perfil de trabalho 


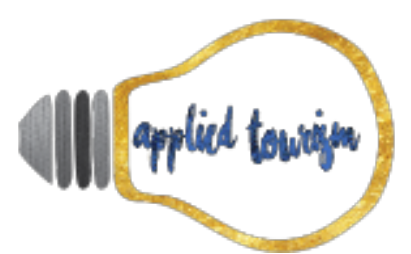

Volume 3, número 1, 2018, p. 36-57

específico - a escala. No caso dos médicos, ainda há a questão dos plantões semanais ou mensais de 12 horas seguidas de trabalho, além da exigência relacionada às jornadas de trabalho de 6, 8, 12 horas seguidas que devem ser cumpridas. Uma parcela ainda sinalizou que trabalha oito horas por semana, sugerindo-se que se tratam dos médicos atuantes em consultórios ou nos postos de saúde. Em relação à questão dos plantões Goldenstein (2013, p. 140), afirma que:

É sabido que o plantão, diurno, noturno, de dia todo, é parte fundamental da vida do médico, independente da escolha da especialidade ou do trabalho e função desempenhada na medicina. O plantão faz parte da formação e do treinamento médico desde os últimos anos do curso médico. É tão presente na vida dos médicos que muitos jovens deixam de optar por estudar medicina e se tornarem médicos por conta da "vida de plantões". Também muitas especialidades são escolhidas exatamente por não requererem os tais plantões. [...] Na maioria das vezes os plantões são fisicamente cansativos e emocionalmente desgastantes. E são desgastantes na medida em que há de se tomar decisões rápidas a respeito de pacientes que pouco se sabe da história clínica e muito menos pessoal.

Em relação às folgas e descansos semanais, os respondentes possuem uma folga por semana, corroborando a alternativa de escalas de trabalho. Houve ainda as respostas: "todo o final de semana" e "aos domingos", que certamente foram assinaladas pelos profissionais que atuam em postos de saúde, onde não ocorrem atendimentos médicos na cidade de Dourados/MS.

Figura 3 - Frequência de períodos de férias.

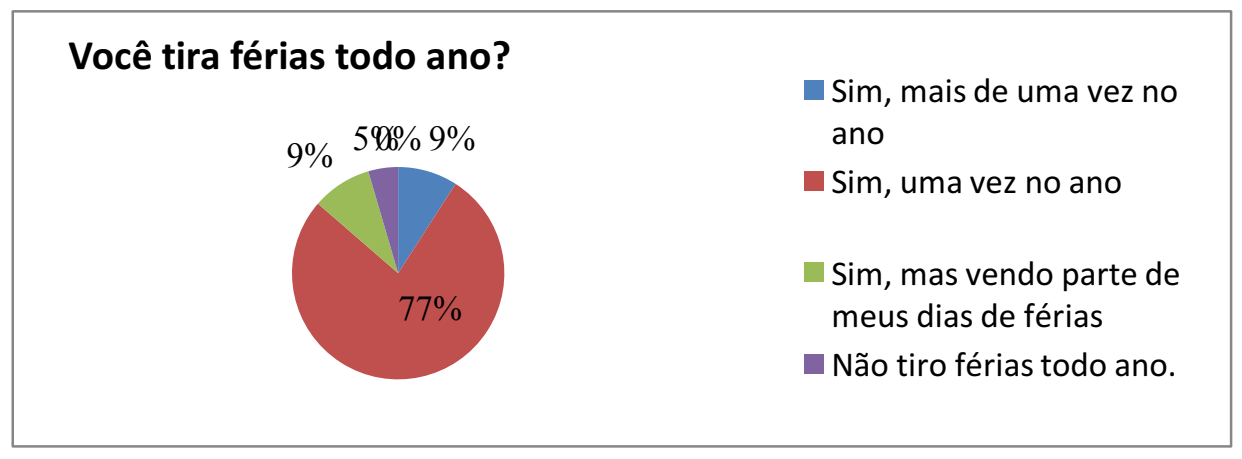

Fonte: Autores (2017). 


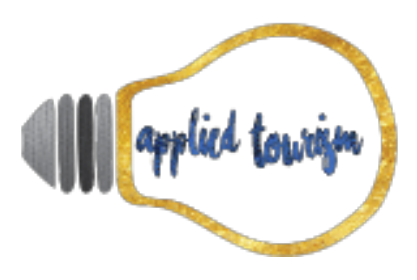

Volume 3, número 1, 2018, p. 36-57

Figura 4 - Atividades realizadas nas férias.

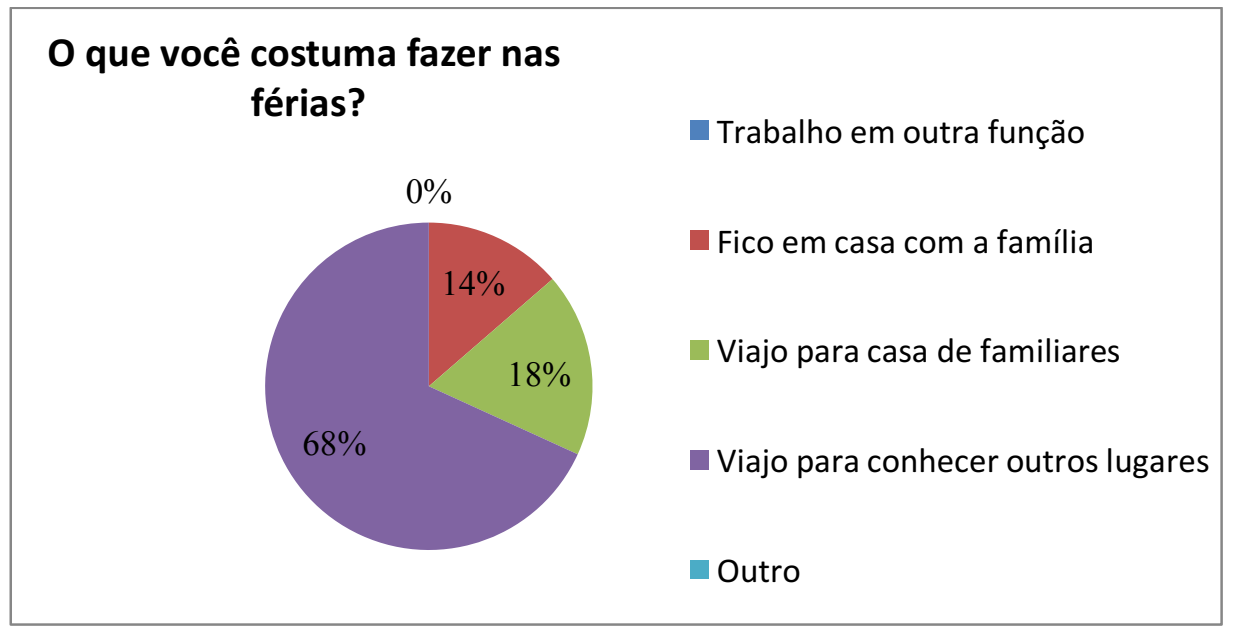

Fonte: Autores (2017).

Buscou-se também analisar a questão das férias dos médicos e as respostas demonstraram que a grande maioria respondeu afirmativamente e que goza as férias uma vez ao ano. Parte dos questionados vendem suas férias e outros gozam férias mais de uma vez por ano. Nesse sentido, nota-se um importante segmento de mercado que diz respeito aos médicos, pois são profissionais que dispõem de algum tempo livre e o dedicam às suas férias. Salienta-se também que este segmento social também incorre em participar de eventos relacionados à sua profissão durante o ano, sobretudo a participação em congressos médicos a fim de se aprimorar e capacitar em suas áreas específicas. Dessa forma, trata-se de um nicho de mercado fundamental a ser pensado e planejado em suas especificidades e necessidades pelos profissionais de turismo.

A questão das férias também é subordinada aos plantões exercidos pelos médicos. Segundo Gondenstein (2011, p. 142), esse procedimento foi atestado em sua pesquisa de campo, sendo que para os médicos entrevistados,

Férias para muitos deles significa ter de deixar o "plantão coberto", alguém substituindo para não sobrecarregarem os colegas. Uma das médicas gostaria de viajar com os amigos, não faltam convites, mas está sempre de plantão em dias feriados ou que antecedem ou vêm imediatamente após. Outra tem o mesmo problema com os pais que fazem pequenas viagens com frequência a convidam e ela está sempre impossibilitada de acompanhá-los. 


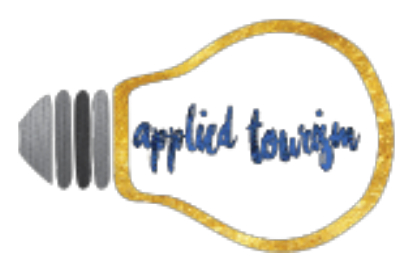

Volume 3, número 1, 2018, p. 36-57

Prosseguindo com a pesquisa, interessou-se por saber o que esses profissionais costumam fazer nas férias, que atividades de lazer e de turismo praticam nesses momentos de tempo livre. A atividade "viagem" foi a considerada de maior relevância nas respostas, corroborando com a justificativa supracitada. Em sua maioria, os médicos de Dourados viajam para conhecer outros lugares e alguns para a casa de familiares e amigos. Uma parcela mínima diz ficar em casa com a família, esse dado provavelmente sugere que os demais membros da família, sobretudo o cônjuge, não comunga com o mesmo período de férias de seu parceiro ou parceira, impossibilitando a viabilidade de viajarem juntos. Por outro lado, mais uma vez se detecta a importância da atividade turística por meio de seus profissionais estarem atentos a essa demanda que viaja pelo menos uma vez por ano, adequando produtos e serviços personalizados a esse segmento social.

Nesse sentido, Krippendorf (1999, pp. 46-51), interpreta e explica as principais motivações para as viagens, dentro das discussões da Sociologia, a saber:

Viajar é descansar, refazer-se: De acordo com essa tese, viajar é reconstruir as forças físicas e psíquicas que a vida cotidiana, o trabalho, a escola e a família esgotaram. Recarregar as baterias. Lubrificar os motores. [...] O lazer e as férias parecem mais necessários do que nunca para proporcionar uma boa saúde.

Viajar é compensar e integrar-se socialmente: A viagem deve contribuir para contrabalancear os déficits e as provações. O turista procura uma compensação pela mobilização unilateral do trabalho: fazer e viver outra coisa, escapar da monotonia e por uma simples mudança, encontrar um derivativo.

Viajar é fugir: Essa tese, a mais difundida de todas, afirma que o ser humano viaja sobretudo em função de um desejo de fuga. Na verdade, esta seria a principal razão de ser do turismo de hoje.

Viajar é comunicar-se: Durante as férias, deseja-se estabelecer contato com outras pessoas, em contrapartida ao anonimato e à ausência de relações humanas que caracterizam a vida do dia a dia. É, antes de tudo, no seu próprio e pequeno círculo, com o cônjuge, a família e os amigos que se procuram os contatos.

Viajar é alargar o próprio horizonte: As necessidades culturais deixam-se facilmente satisfazer com doses homeopáticas, sob a forma de simples curiosidades.

Viajar é ser livre e independente: A viagem nos libera das coerções.

Viajar é partir para a descoberta de si mesmo: Segundo tal tese, a viagem proporciona-nos a consciência da nossa própria realidade.

Viajar é ser feliz: As expectativas ligadas as férias são esperanças de felicidade.

Viajar é...: A lista das interpretações poderia se alongar à vontade, apenas as contradições seriam mais numerosas. 


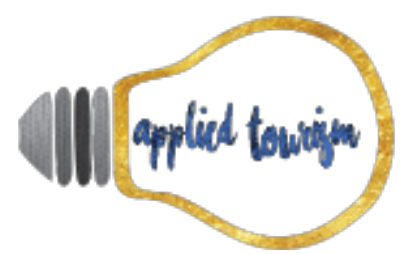

Volume 3, número 1, 2018, p. 36-57

Figura 5 - Atividades realizadas nas folgas do trabalho

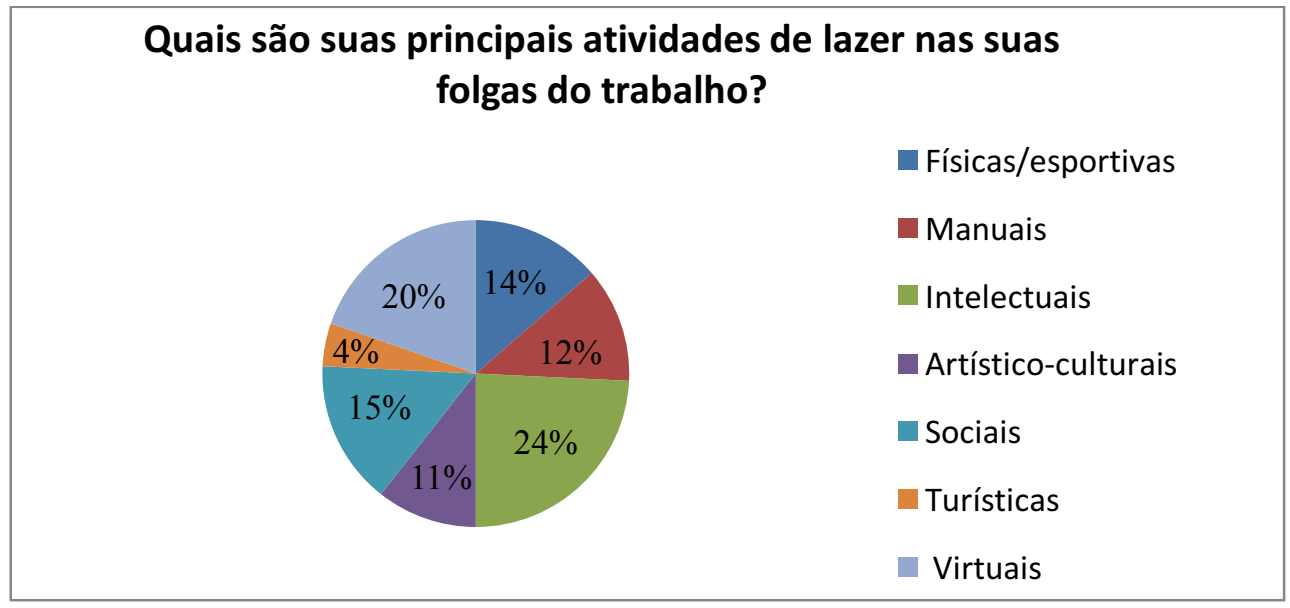

Fonte: Autores (2017).

Esta questão foi inspirada nos conhecimentos teóricos abordados na disciplina "Sociologia do Lazer e do Turismo". Elaborou-se a mesma tendo por base as categorias de interesse no lazer investigada por Dumazedier (1980): físicas e esportivas, manuais, intelectuais, artísticoculturais e sociais. Além disso, acrescentou-se também a categoria conceituada por Camargo (1998), a turística, além da de Schwartz (2003), a virtual. Outrossim, o respondente tinha a possibilidade de assinalar até três alternativas, caso quisesse. Assim, as respostas compreenderam aspectos bastante diversos das categorias de interesse pelo lazer, salientando que foram apontadas algumas atividades proeminentes específicas relacionadas a cada categoria, as quais se expressam de acordo com a ordem crescente das respostas: Intelectuais (16 apontamentos): como leitura de livros, filmes documentários, programas educativos; Virtuais (13 apontamentos): jogos virtuais e todos os tipos de lazeres virtuais, como por exemplo Facebook, Instagram, Snap Chat, jogos eletrônicos, dentre outros; Sociais (10 apontamentos): sair em grupos religiosos, rodas de tereré, festas familiares, bares; Físicas/esportivas ( 9 apontamentos): como a caminhada, a ginástica, a academia e o esporte; Manuais (8 apontamentos): como os cuidados com plantas, animais, cuidados com a casa; Artístico-culturais (7 apontamentos): como os espetáculos, a dança, o cinema e o teatro; Turística (3 apontamentos): como viagens, pequenos passeios, visitação turística. Diante desse contexto, nota-se a importância de um planejamento na área do lazer e do turismo adequados aos interesses do grupo social ao qual estão vinculados os profissionais 


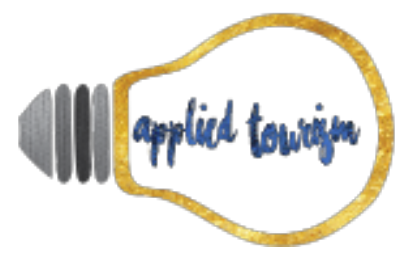

Volume 3, número 1, 2018, p. 36-57

do turismo. Executar serviços e vender produtos de lazer e de turismo de qualidade tornouse imprescindível, já que os interesses desse segmento social revelam-se bastante diversificados.

Figura 6 - Atividades desejadas

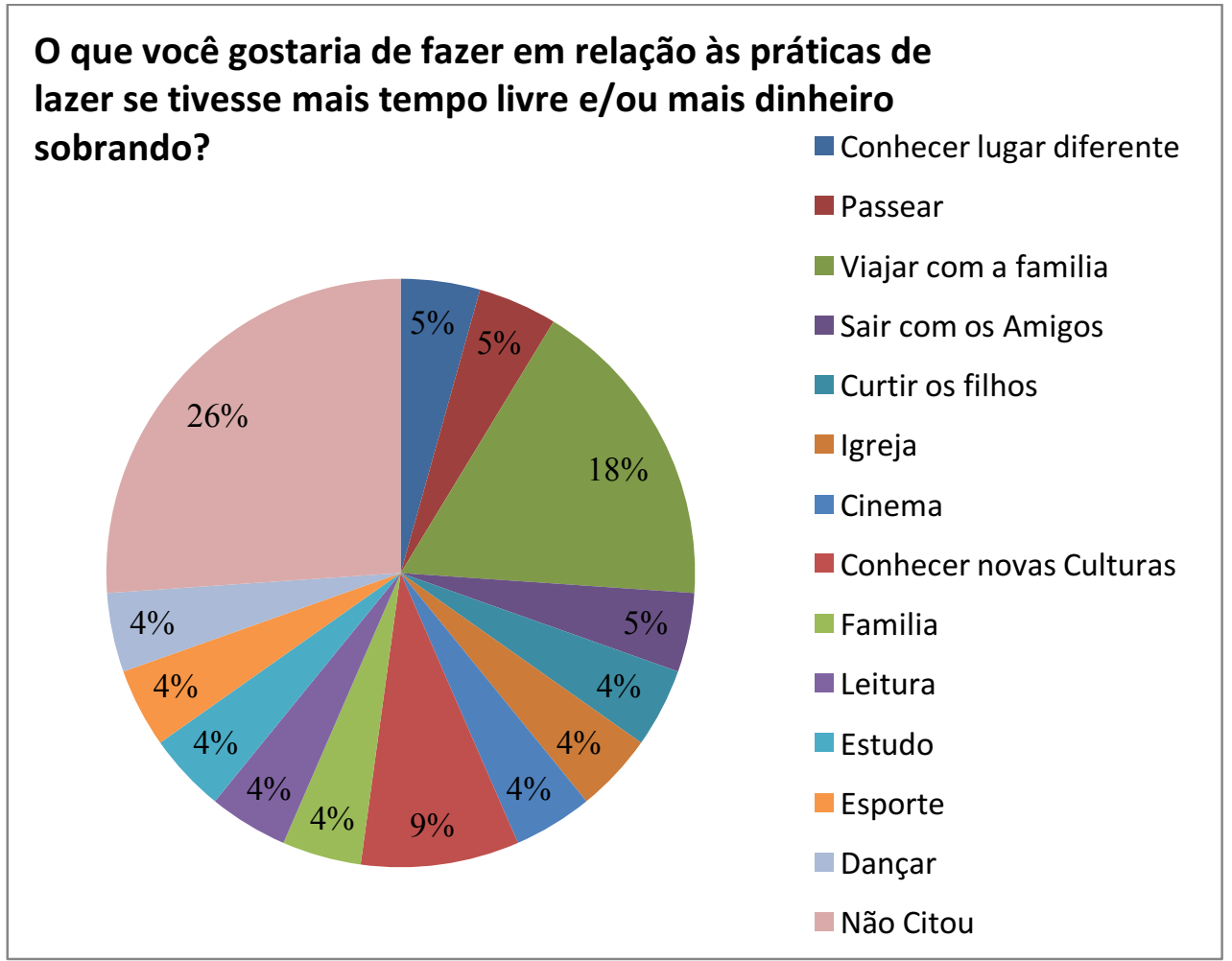

Fonte: Autores (2017).

Finalmente, na última questão, os respondentes apontaram as atividades de lazer as quais gostariam de realizar se tivessem mais tempo e/ou dinheiro sobrando. Essa questão, diferentemente das demais anteriores, era aberta justamente para deixar o médico à vontade para responder o que quisesse, ou seja, ele poderia "sonhar". O objetivo era que expressasse suas vontades e desejos em relação às práticas de lazer, por isso justamente a questão do tempo e do dinheiro, muito apontadas nas pesquisas como sendo impeditivos das práticas de lazer e turismo contemporâneas. Nesse sentido, os apontamentos foram muito diversos, sobressaindo infelizmente, a alternativa "não citou". Sugere-se que aqui, o respondente que estava em seu horário de trabalho, não se dedicou a pensar sobre essa 


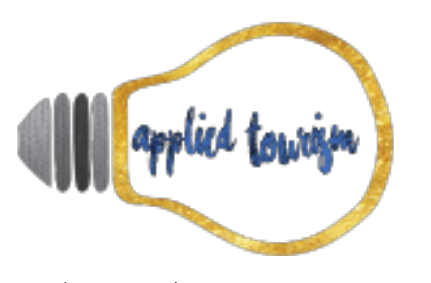

Volume 3, número 1, 2018, p. 36-57

questão, preferindo deixá-la em branco. Dos que responderam, a maioria apontou atividades relacionadas à família; ficar, interagir e viajar com a família; relacionar-se com os filhos. Certamente porque os médicos passam longos períodos de tempo trabalhando em escalas, além de atenderem em diversos locais de trabalho, exaurindo-se, assim, o tempo livre com a família. Outras respostas dizem respeito às atividades ligadas à cultura, intelectuais e esportivas.

Krippendorf (1999) também mostrou uma enorme variedade em relação à escolha dos seus pesquisados em relação às práticas de lazer e as atividades que mais praticam em suas férias, demonstrando que as motivações são diversas, porém buscam um comportamento de mudança no cotidiano, sendo que as atividades mais buscadas, segundo o autor, são: passeios, excursões, conversar com outras pessoas, dormir, descansar, ir a restaurantes, fazer caminhadas, visitar museus, comer, dentre outros.

\section{ATIVIDADES DE LAZER E TURISMO: PROPOSTAS PARA O SEGMENTO MÉDICO EM DOURADOS/MS}

Diante dos resultados da pesquisa, notou-se a necessidade de se planejar atividades de lazer e de turismo para o segmento estudado. Nesse sentido, buscou-se, de acordo com o levantamento dos dados relacionados às necessidades dos médicos, organizar momentos e situações em que os mesmos pudessem vivenciar experiências de lazer e de turismo, adequados ao seu perfil de trabalho e convívio social. Entende-se que o lazer não pode ser deixado para segundo ou terceiro plano na vida desses profissionais, mesmo estando inseridos em rotinas de trabalhos estressantes que perpassam as escalas laborais. O lazer, além de amenizar as tensões das rotinas de trabalho, pode constituir-se numa melhora de qualidade de vida, no ambiente familiar e no profissional. Segundo Rocha \& Delconti (n.d., p. 2): 


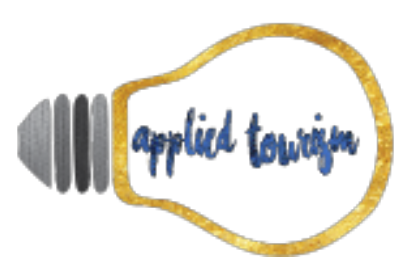

Volume 3, número 1, 2018, p. 36-57

trabalho e as necessidades familiares, religiosas e sociais desta sociedade. A qualidade de vida, de acordo com Minayo (2000, p. 8) "é uma noção eminentemente humana, que tem sido aproximada ao grau de satisfação encontrado na vida familiar, amorosa, social, ambiental e também na própria estética existencial". No entanto, esses elementos que definem a qualidade de vida estão muito próximos das definições atribuídas à noção de lazer.

Assim, ao analisar as respostas dos médicos em relação às suas práticas de lazer, algumas realizadas, outras almejadas e, ainda, sob o olhar da teoria das categorias das atividades de lazer de Dumazedier (1980), Camargo (1998) e Schwartz (2003), esboçamos três propostas no sentido de se constituírem em possibilidades de lazer de descanso para os médicos, objetivando uma melhor qualidade de vida.

A primeira proposta versa sobre um programa de ginástica laboral, fundamental para o bom desempenho durante as escalas de trabalho. Sabe-se dos inúmeros benefícios de tal atividade, como por exemplo: prevenção de possíveis doenças, diminuição do sedentarismo, melhora no condicionamento físico e autoestima, redução da fadiga, combate as tensões, aumenta a produtividade no trabalho, diminuição das faltas e afastamentos para tratamento médico, além dos benefícios fisiológicos relacionados, sobretudo ao sistema cardíaco e respiratório. Sampaio \& Oliveira (2008, pp. 76-77) classificam a ginástica laboral em quatro categorias: preparatória (realizada antes de se iniciar a jornada de trabalho), compensatória (objetiva trabalhar os músculos que estão sendo utilizados com mais frequência na atividade laboral), de relaxamento (praticada ao final da jornada de trabalho) e corretiva (tem por finalidade recuperar lesões, limitações e condições ergonômicas). Dessa forma, sugere-se que os médicos pesquisados sejam atendidos por equipes multidisciplinares a fim de auxiliá-los nessa atividade durante suas escalas e que de nenhuma maneira terá um impacto negativo em relação aos atendimentos, já que tal atividade é realizada por um tempo curto, em torno de dez a vinte minutos por dia.

A segunda proposta vem de encontro às necessidades apontadas pelos médicos durante a pesquisa e às atividades de lazer mais praticadas ou almejadas pelos mesmos. As respostas, em sua maioria, relacionam-se ao lazer virtual, intelectual e cultural. Nesse sentido, e de 


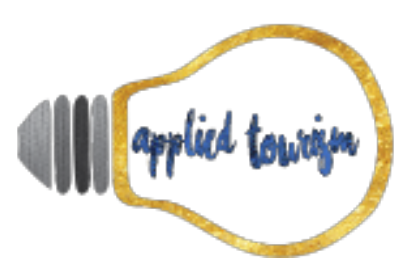

Volume 3, número 1, 2018, p. 36-57

acordo com as possibilidades individuais e condições estruturais dos estabelecimentos médicos visitados, propõem-se uma sala específica para o descanso e o lazer dos médicos. Para essa sala, sugere-se uma infraestrutura contendo uma pequena biblioteca com livros diversos, uma revistaria, poltronas adequadas ao descanso, uma rede, uma mesa de pinguepongue, uma máquina de café, uma televisão acompanhada de uma pequena coleção de filmes e documentários, um aparelho de videogame com jogos que estimulem a mente e também o corpo, além de outros itens que se adéquam aos objetivos do projeto. Essa sala seria dedicada ao descanso dos médicos e promoveria simultaneamente o lazer e a interação dos colegas que estivessem em um intervalo na escala de trabalho.

Nesse contexto, Oliveira (n.d., p. 01) destaca que a qualidade de vida do profissional está intrinsecamente relacionada com a qualidade de vida no ambiente de trabalho, pois

[... o trabalho assume papel central na vida das pessoas, chegando a definir aspectos vitais como "status" e identidade pessoal. Assim sendo, o trabalho deve ser realizado em condições que ajudem a promover a saúde, o equilíbrio físico e psicoemocional e, em consequência, o bem-estar total do indivíduo, refletindo a importância que tem para o trabalhador.

A autora ainda destaca o papel das áreas de lazer internas nas empresas como sendo um dos aspectos que possibilitam a melhora na qualidade de vida dos indivíduos, além de promover a

\footnotetext{
Integração e lazer: clima de camaradagem no ambiente de trabalho, incentivo a participação dos funcionários em projetos filantrópicos, forte política de recepção e integração aos novos, clube, colônia de férias, área de lazer na empresa com sala de jogos, leitura e ginástica, atividades de recreação para os filhos de funcionários, promoção de festas Juninas e de Natal (Oliveira, n.d., p. 1).
}

A terceira e última proposta realizada pelo grupo de pesquisadoras diz respeito à atividade turística, pois, de acordo com o segmento pesquisado, é evidente a preocupação com as questões familiares, o desejo de praticar o lazer com a família, sobretudo os filhos. Dessa forma, a sugestão é de que os hospitais particulares e os postos de saúde sejam visitados por agentes de viagens que apresentarão pacotes direcionados às necessidades específicas desses clientes. Tais pacotes devem ser organizados a partir da motivação cultural, pois a 


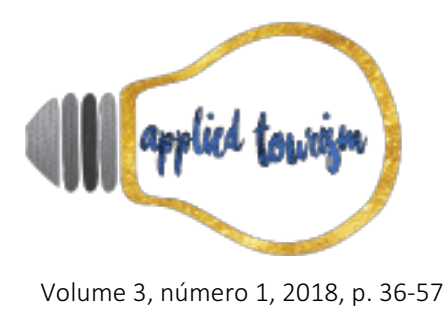

mesma foi apontada enquanto desejo de prática de lazer, além de se implementar atividades de turismo que reúnam a família. Os destinos, bem como as atividades planejadas, deverão ser direcionados aos membros da família enquanto grupo, optando-se sempre em agregar valor aos pacotes personalizados e orientados para a prática turística dos médicos. Dessa forma, a questão da qualidade de vida vem de encontro ao que propõem Minayo et al. (2000) quando afirmam que o bem-estar dos indivíduos está relacionado aos diferentes momentos em que interagem nos âmbitos sociais, sejam no âmbito familiar, de trabalhos ou com outros grupos sociais.

Outra possibilidade dentro dessa proposta está nos chamados "Dia de Lazer", onde é escolhido determinado destino que seja na mesma cidade ou próximo à cidade onde os trabalhadores moram para que os mesmos tenham num determinado dia de folga, ações e atividades de relaxamento, diversão em família, visitação a atrativos turísticos, dentre outras atividades. Nesse sentido, a convivência em família, tão desejada pelos médicos, seria plenamente incorporada às propostas aqui definidas.

\section{CONCLUSÃO}

Este artigo teve como intuito demonstrar os resultados do projeto que abordou a temática da análise sociocultural das práticas de lazer de um grupo de médicos que trabalham em equipamentos públicos e particulares na cidade de Dourados/MS. O objetivo geral foi verificar como os médicos compreendiam seu tempo livre, de que modo utilizavam esse tempo e ainda, qual parte desse tempo era destinada à prática de atividades de lazer e de turismo.

Nesse sentido, definimos como concepção de lazer a ser utilizada na pesquisa como uma forma do indivíduo utilizar seu tempo dedicando-se a uma atividade que goste de fazer, o que não significa que seja sempre uma mesma atividade. Esta atividade pode ser uma entre tantas outras. Assim, quando gastamos nossas energias no trabalho, esquecemos que precisamos também de energia para o lazer. Porém, sabe-se que o lazer relaciona-se 


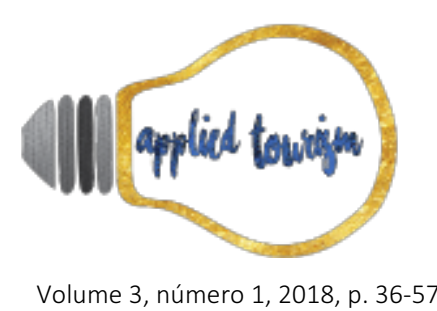

intrinsecamente com o trabalho e vice-versa, não podendo ser desvinculados tais conceitos e desdobramentos em nossa sociedade contemporânea.

Dessa forma, depois de aplicada a metodologia definida para essa pesquisa e o método de questionário aos vinte e dois respondentes, obtivemos que o perfil sociocultural do segmento pesquisado é formado basicamente por médicos que: em sua maioria são homens, com uma faixa etária bastante diversificada, porém majoritariamente entre 36 e 45 anos, grande parte casada, com ensino superior e pós-graduação. Indagados sobre a carga horária de trabalho semanal, a maioria evidenciou que não tem limites de horas para trabalhar por semana, demonstrando, assim, um perfil de trabalho específico - a escala. Há ainda a questão dos plantões semanais ou mensais de 12 horas seguidas de trabalho, além da exigência relacionada às jornadas de trabalho de 6,8,12 horas seguidas que devem ser cumpridas. Em relação à questão das férias dos médicos, as respostas demonstraram que a grande maioria respondeu afirmativamente gozar uma vez ao ano. Parte dos questionados vendem suas férias e outros gozam férias mais de uma vez por ano. Nesse sentido, nota-se um importante segmento de mercado que diz respeito aos médicos, pois são profissionais que dispõem de algum tempo livre e o dedicam às suas férias. Salienta-se também que este segmento social também incorre em participar de eventos relacionados à sua profissão durante o ano, sobretudo a participação em congressos médicos a fim de se aprimorar e capacitar em suas áreas específicas. Dessa forma, trata-se de um nicho de mercado fundamental a ser pensado e planejado pelos profissionais de turismo. Uma parcela mínima diz ficar em casa com a família, esse dado muito provavelmente sugere que os demais membros da família, sobretudo o cônjuge, não comunga com o mesmo período de férias de seu parceiro ou parceira, impossibilitando a possibilidade de viajarem juntos. Assim, as respostas compreenderam aspectos bastante diversos das categorias de interesse pelo lazer, salientando que foram apontadas algumas atividades proeminentes específicas relacionadas a cada categoria.

Ao término deste projeto de pesquisa com o grupo social "médicos", concluímos que os mesmos têm disponibilizado pouco tempo para seu lazer e abrindo mão, muitas vezes, de seus momentos pessoais em detrimento aos cuidados com a saúde de seus pacientes. Por 


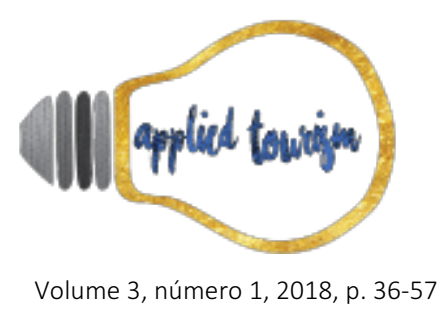

outro lado, mais uma vez se detecta a importância da atividade turística por meio de seus profissionais estarem atentos a essa demanda que viaja pelo menos uma vez por ano, adequando produtos e serviços adequados e personalizados a esse segmento social.

Nesse sentido, a pesquisa propôs três tipos de atividades diferenciadas que poderão auxiliar o segmento estudado a desenvolver atividades e momentos de lazer, para que, dessa forma, os pesquisados possam melhorar sua qualidade de vida, além de se perceberem enquanto indivíduos que têm necessidades diversas e, dentre as quais, estão as atividades de lazer e de turismo. Tais atividades podem ser implementadas a curto e médio prazo, alterando consideravelmente a qualidade laboral, familiar e individual dos médicos em Dourados/MS.

\section{REFERÊNCIAS}

Camargo, L. O. L. (1999). O que é lazer. 3. ed. São Paulo: Brasiliense.

Camargo, L. O. L. (1998). Educação para o lazer. São Paulo: Moderna.

De Masi, D. (2000). O ócio criativo. Rio de Janeiro: Sextante.

Dumazedier, J. (1999). Sociologia empírica do lazer. 2. ed. São Paulo: Perspectiva: SESC.

Dumazedier, J. (1976). Lazer e cultura popular. São Paulo: Perspectiva.

Dumazedier, J. (1980). Valores e conteúdos culturais do lazer. São Paulo: SESC.

Goldenstein. E. (2013). Quando os médicos (des)cansam: trabalho e lazer na vida de um grupo de médicos. São Paulo: Casa do Psicólogo.

Goldenstein. E. (2011). Quando os médicos des-cansam: compreendendo o sentido que médicos de um hospital público dão ao tempo livre, trabalho e lazer. São Paulo: PUC/SP.

Krippendorf, J. (1999). Sociologia do Turismo: para uma nova compreensão do lazer e das viagens. São Paulo: Aleph. 


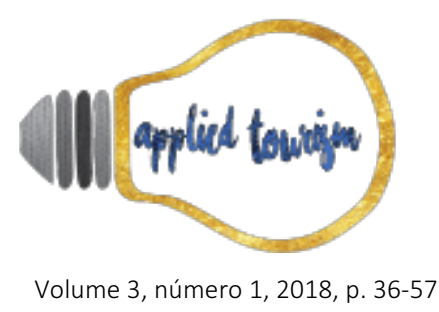

Minayo, M. C. S. et al. (2000). Qualidade de vida e saúde: um debate necessário. Rev. Ciência e Saúde Coletiva. Vol. 5, n. 1. Rio de Janeiro.

Oliveira, R. (n. d.). Benefícios especiais geram qualidade de vida na empresa. Acesso em: 18 de agosto de 2017, disponível em: < http://www.roselisoriano.com.br/beneficios-especiaisgeram-qualidade-de-vida-na-empresa/ >

Rocha, B. R. \& Delconti, W. L. (n. d.) A relação entre o lazer e a qualidade de vida: indicativos à atuação do profissional em Educação Física. Acesso em: 18 de agosto de 2017, disponível em: http://www.educadores.diaadia.pr.gov.br/arquivos/File/fevereiro2012/educacao_fisica_artigos/rela cao_lazer_qualidade_vida.pdf $>$.

Rolim, L. C. (1989). Educação e lazer: a aprendizagem permanente. São Paulo: Ática.

Sampaio, A. A. \& Oliveira, J. R. G. (2008). A ginástica laboral na promoção da saúde e melhoria da qualidade de vida no trabalho. Caderno de Educação Física. Vol 7, n. 13, 2. sem. 2008, pp. 71-79.

Schwartz, G. M. (2003). O conteúdo virtual do lazer: contemporizando Dumazedier. Revista Licere, Belo Horizonte, Vol. 6, n. 2, pp. 23-31. 